\title{
Development of a Stability-Indicating HPLC Method for Simultaneous Determination of Amlodipine Besylate and Atorvastatin Calcium in Bulk and Pharmaceutical Dosage Form
}

\section{Hafez HM*, Elshanawany AA, Abdelaziz LM and Mohram MS}

Bachelor Degree of Pharmaceutical Science, Zagazig University

\section{Introduction}

Hypertension and dyslipidemia are two most commonly cooccurring cardiovascular risk factors. Coronary artery disease (CAD) is the leading cause of morbidity and mortality worldwide accounting for in excess of 930,000 deaths. It is a multifactorial disease, emphasis is to treat overall cardiovascular risk, rather than single risk factors in isolation .The third National Health and Nutrition Examination Survey (NHANES) estimated that more than $64 \%$ of patients with hypertension also have dyslipidemia; conversely, approximately $47 \%$ of patients with dyslipidemia have hypertension. Antihypertensive and lipid lowering medications substantially reduce the risk of CAD, stroke, and death in patients with cardiovascular risk factors.

The fixed dose combination containing the antihypertensive agent amlodipine and the statin, atorvastatin, is the first combination of its kind designed to treat two risk factors for cardiovascular disease (CVD). The pharmacokinetic and pharmacodynamic properties of amlodipine and atorvastatin make them well suited for combination in a single pill to manage cardiovascular risk. The half lives of both agents facilitate once daily dosing, and both can be administered at any time of day with or without food. These drugs have no adverse effects on the other's efficacy or tolerability [1].

CADUET (amlodipine besylate and atorvastatin calcium) tablets combine the calcium channel blockeramlodipine besylate with the HMG CoA-reductase inhibitor atorvastatin calcium. Amlodipine besylate is chemically described as 3-ethyl-5-methyl (4RS)-2-[(2aminoethoxy) methyl]-4-(o-chlorophenyl)-6-methyl-1, 4-dihydro pyridine-3, 5-dicarboxylate benzene sulphonate, its empirical formula is $\mathrm{C}_{20} \mathrm{H}_{25} \mathrm{ClN}_{2} \mathrm{O}_{5} \cdot \mathrm{C}_{6} \mathrm{H}_{6} \mathrm{O}_{3} \mathrm{~S}$. Atorvastatin calcium is chemically described as calcium [R-(3R, 5R)]-7-[2-(4-fluorophenyl)-5-(1methylethyl)-3-phenyl-4-(phenyl carbamoyl)-1H-pyrrol-1-yl] -3 , 5-dihydroxy heptanoatetrihydrate. Its empirical formula is $\left(\mathrm{C}_{33} \mathrm{H}_{34}\right.$ $\left.\mathrm{FN}_{2} \mathrm{O}_{5}\right)_{2} \mathrm{Ca} \cdot 3 \mathrm{H}_{2} \mathrm{O}$. The structural formulae for amlodipine besylate and atorvastatin calcium are shown below Figure 1 .

CADUET contains amlodipine besylate, a white to off-white crystalline powder, and atorvastatin calcium, also a white to off-white crystalline powder. Amlodipine besylate has a molecular weight of 567.1 and atorvastatin calcium has a molecular weight of 1209.42. Amlodipine is slightly soluble in water and sparingly soluble in ethanol. Atorvastatin calcium is insoluble in aqueous solutions of $\mathrm{pH} 4$ and below. Atorvastatin is very slightly soluble in distilled water, $\mathrm{pH} 7.4$ phosphate buffer, and acetonitrile; slightly soluble in ethanol; and freely soluble in methanol. Caduet (amlodipine and atorvastatin) is indicated in patients for Hypertension, Coronary Artery Disease (CAD) like Angina, Prevention of Cardiovascular Disease and Hyperlipidemia [2].

The preparation of new combinations of drugs in pharmaceuticals for pharmacological activity development, as well as the requirements of modern industrial-scale pharmaceutical analysis, encourages researchers to develop new and efficient methods for multi- quantification with separation procedures. High performance liquid chromatography is a dominant separation technique, especially in pharmaceutical analysis [3].

Literature survey indicated that several analytical methods have been described for the determination of active ingredients (Amlodipine Besylate and Atorvastatin Calcium) each alone [4,5], in combination with other compound [6,7]. Several method were reported for simultaneous determination of them together like Spectrophotometry [8-10], HPTLC [11] Spectrofluorimetry, HPLC

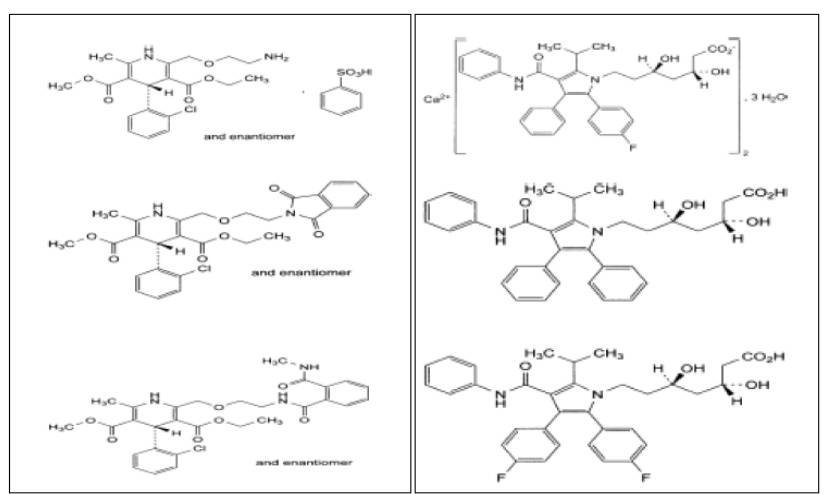

Figure 1: Structures of Amlodipine Besylate, Amlodipine impurity A Amlodipine impurity B, Atorvastatin Calcium, Atorvastatin impurity $A$ and Atorvastatin impurity $C$ respectively

Amlodipine impurity $\mathbf{A}$ is 3-ethyl 5-methyl (4RS)-4-(2-chlorophenyl)-2[[2-(1,3-dioxo-1,3-dihydro-2H-isoindol-2-yl)ethoxy]methyl]-6-methyl-1,4dihydropyridine-3,5-dicarboxylate

Amlodipine impurity $\mathbf{B}$ is 3-ethyl 5-methyl (4RS)-4-(2-chlorophenyl)6-methyl-2-[[2- [[2-(methylcarbamoyl)benzoyl]amino]ethoxy]methyl]-1,4dihydropyridine-3,5-dicarboxylate

Atorvastatin impurity $\mathbf{A}$ is $(3 R, 5 R)$ - 3, 5-dihydroxy -7-[5-(1-methylethyl)-2 3-diphenyl-4-(phenyl carbamoyl)-1H-pyrrol-1-yl] - heptanoic acid (desfluoroatorvastatin).

Atorvastatin impurity $\mathbf{C}$ is $(3 \mathrm{R}, 5 \mathrm{R})-7-[2, \quad 3-\mathrm{bis}$ (4-fluorophenyl) -5-(1-methylethyl) -4-(phenyl carbamoyl)-1H-pyrrol-1-yl] - 3, 5-dihydroxy heptanoic acid (fluoroatorvastatin).

*Corresponding author: Hafez HM, Bachelor degree of Pharmaceutical Science, Zagazig University, Zagazig, Egypt, Quality Control Department, EIPICO, 10th Ramadan, Egypt, Tel: 020113231458; E-mail: hanyhaf_1982@yahoo.com

Received August 31, 2014; Accepted October 17, 2014; Published October 20, 2014

Citation: Hafez HM, Elshanawany AA, Abdelaziz LM, Mohram MS (2014) Development of a Stability-Indicating HPLC Method for Simultaneous Determination of Amlodipine Besylate and Atorvastatin Calcium in Bulk and Pharmaceutical Dosage Form. Pharm Anal Acta 5: 316. doi:10.4172/2153-2435.1000316

Copyright: $\odot 2014$ Hafez HM, et al. This is an open-access article distributed under the terms of the Creative Commons Attribution License, which permits unrestricted use, distribution, and reproduction in any medium, provided the original author and source are credited. 
Citation: Hafez HM, Elshanawany AA, Abdelaziz LM, Mohram MS (2014) Development of a Stability-Indicating HPLC Method for Simultaneous Determination of Amlodipine Besylate and Atorvastatin Calcium in Bulk and Pharmaceutical Dosage Form. Pharm Anal Acta 5: 316. doi:10.4172/2153-2435.1000316

Page 2 of 9

Coupled with Fluorescence Detection [12] Capillary Electrophoresis [3] HPLC Coupled with UV Detection [13-17], HPLC-MS-MS [1820], RP-UPLC [21,22]. Stability testing and stress testing (forced degradation studies) are critical components of drug development strategy. The studies help us understand the mechanism of a drug's decomposition, which further helps in obtaining information on physical and chemical factors that result in instability. These factors are then controlled in order to stabilize the drug or drug formulation, resulting in increased shelf-life or improved efficacy [23]. Stress testing is defined as the stability testing of drug substances and drug products under conditions exceeding those used for accelerated testing. These studies are undertaken to elucidate the intrinsic stability of the drug substance. According to International Conference on Harmonization (ICH) guideline Q1A (R2), the stability testing of drug substances should be carried out under different stress conditions (hydrolysis, oxidation, photolysis, and thermal degradation) to validate the stability-indicating supremacy of analytical methods used for the analysis of stability samples [24]. The standard conditions for photo stability testing are described in ICH guideline Q1B [25]. These tests allow accurate and precise quantification of drugs and their degradation and interaction products. Few analytical methods have been reported as stability indicating methods for simultaneous determination of amlodipine and atorvastatin in presence of their degradation products [26-29]. The focus of the present study was to develop a simple, rapid, precise, and accurate isocratic reversed-phase stability-indicating HPLC method for the simultaneous determination of amlodipine and atorvastatin and their impurities in tablet dosage form.

\section{Experimental}

\section{Instrumentation}

Analysis was performed on a chromatographic system of WATERS 2695 separation module connected to WATERS 2487 UV/VIS detector. The system equipped by Empower PC program. The chromatographic separation was achieved on Phenomenex $(100 \times 4.6 \mathrm{~mm})$

\section{Chemicals and reagents}

All reagents used were of analytical grade or HPLC grade. Potassium dihydrogen phosphate and ortho-phosphoric acid were supplied by (Merck, Darmstadt, Germany), Acetonitrile and Methanol HPLC grade were supplied by (Fischer scientific, U.K.) and Distilled water.

(Note: The water used in all the experiments was obtained from Milli-RO and Milli-Q systems (Millipore, Bedford, MA).

Amlodipine Besylate and Atorvastatin Calcium working standard powders were kindly supplied by Egyptian international pharmaceutical industries company (EIPICO) $\left(10^{\text {th }}\right.$ Ramadan, Egypt), and were used without further purification.

\section{Pharmaceutical preparation}

Caduet, Pfizer(Egypt) contains (Amlodipine (as Besylate) $10 \mathrm{mg}$ per tablet and Atorvastatin and Atorvastatin (as Calcium) $10 \mathrm{mg}$ per tablet) B.NO: 0795049.

\section{Chromatographic condition}

$20 \mu$ l of drugs sample solutions were monitored at fixed wavelength (lambda $=240 \mathrm{~nm}$ for amlodipine Besylate and atorvastatin Calcium). Liquid chromatography was performed on Phenomenexkinetex $2.6 \mu \mathrm{m}$ C18 100A $(100 \times 4.6 \mathrm{~mm})$, and the mobile phase consisted of Potassium dihydrogen phosphate ( $\mathrm{pH} 5.5,0.03 \mathrm{M})$-Acetonitrile (65:35 V/V) which pumped at a flow rate equals to $1.2 \mathrm{ml} / \mathrm{min}$ at $40^{\circ} \mathrm{C}$.

Potassium dihydrogen phosphate ( $\mathrm{pH} 5.5,0.03 \mathrm{M}$ ) was prepared by dissolving $4.08 \mathrm{~g}$ Potassium dihydrogen phosphate in approximately $950 \mathrm{ml}$ distilled water. The $\mathrm{pH}$ was adjusted to 5.5 with sodium hydroxide. Water was added to $1000 \mathrm{ml}$. Mobile phase was filtered through a $0.45 \mu \mathrm{m}$ Nylon membrane filter (Millipore, Milford, MA, USA) under vacuum and degassed by ultrasonication (Cole Palmer, Vernon Hills, USA) before usage. Mixture of acetonitrile and distilled water $(50: 50 \mathrm{~V} / \mathrm{V})$ was prepared to be used as diluent.

\section{Preparation of stock standard solutions}

Stock standard solutions containing $1 \mathrm{mg} / \mathrm{ml}$ of Amlodipine (as Besylate) (actual weight $=103.6 \mathrm{mg}$ ) and $1 \mathrm{mg} / \mathrm{ml}$ of Atorvastatin (as Calcium) (actual weight=105.2 mg ) were prepared by dissolving 100 $\mathrm{mg}$ of each in $40 \mathrm{ml}$ methanol in $100 \mathrm{ml}$ volumetric flask respectively. It was sonicated for 5 minutes and the final volume of solutions was made up to $100 \mathrm{ml}$ with diluent to get stock standard solutions.

\section{Preparation of calibration plot (working standard solutions)}

To construct calibration plots, the stock standard solutions were diluted with diluent to prepare working solutions in the concentration ranges $(5-15 \mu \mathrm{g} / \mathrm{ml}$ ) for Amlodipine Besylate and Atorvastatin Calcium. Each solution $(n=5)$ was injected in triplicate and chromatographed under the mentioned conditions above. Linear relationships were obtained when average drug standard peak area were plotted against the corresponding concentrations for each drug. Regression equation was computed.

\section{Sample preparation}

A composite of ten Caduet10/10 tablets was prepared by grinding it to a fine, uniform size powder, triturated using mortar and pestle. After calculating the average tablet weight, amounts of powder equivalent to $10 \mathrm{mg}$ for both drugs was accurately weighed and transferred to $100 \mathrm{ml}$ volumetric flasks then complete with diluent up to $100 \mathrm{ml}$. The solutions were sonicated for $15 \mathrm{~min}$ and the solutions were then filtered through $0.45 \mu \mathrm{m}$ Nylon membrane filters (Millipore, Milford, MA, USA). Aliquots of appropriate volume $(10 \mathrm{ml})$ were transferred to $100 \mathrm{ml}$ calibrated flasks and diluted to volume with diluent to obtain the mentioned concentration above $(10 \mu \mathrm{g} / \mathrm{ml})$. The diluted solutions were analyzed under optimized chromatographic conditions and chromatogram is showed in (Figure 2A).

\section{Forced degradation of amlodipine besylate and atorvastatin calcium}

To determine the proposed method as a stability-indicating method for Amlodipine Besylate, Atorvastatin Calcium and Caduet tablets bulk powders were stressed under different conditions in forced degradation studies. Stock solutions of Amlodipine Besylate, Atorvastatin Calcium and Caduet tablets bulk powders-used to forced degradation studieswere prepared by dissolving it in diluent [30].

Acidic degradation: Hydrochloric acid $(\mathrm{HCl})(1 \mathrm{M}, 10 \mathrm{ml})$ was added to $10 \mathrm{ml}$ prepared stock solutions of Amlodipine Besylate, Atorvastatin Calcium and Caduet tablets respectively. These solutions were separately heated at $70^{\circ} \mathrm{C}$ for 6 hours in the dark (to exclude the possible degradative effect of light). The solutions $(2 \mathrm{ml})$ were then transferred to $25 \mathrm{ml}$ volumetric flasks, neutralized by addition of $1 \mathrm{ml}$ of $1 \mathrm{M} \mathrm{NaOH}$ and diluted to final volume with diluent $[25,30,31]$. 
Citation: Hafez HM, Elshanawany AA, Abdelaziz LM, Mohram MS (2014) Development of a Stability-Indicating HPLC Method for Simultaneous Determination of Amlodipine Besylate and Atorvastatin Calcium in Bulk and Pharmaceutical Dosage Form. Pharm Anal Acta 5: 316. doi:10.4172/2153-2435.1000316

Page 3 of 9

$\underline{\mathbf{A}-}$

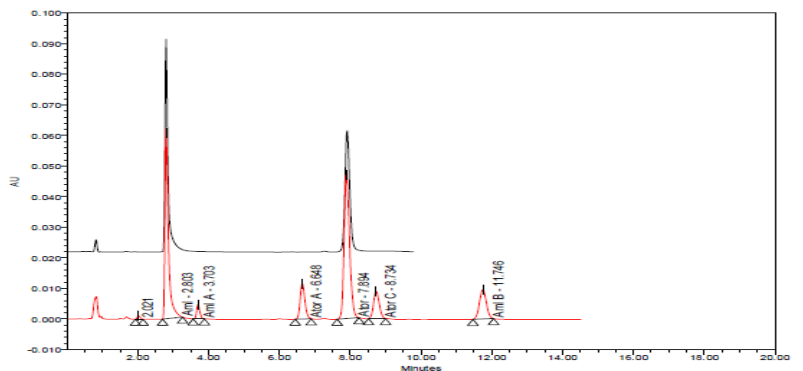

$\underline{\text { B- }}$

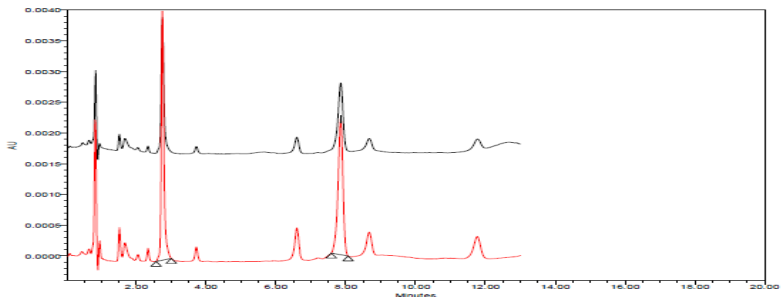

Figure 2: A and B: Typical HPLC chromatograms obtained from $20 \mu$ injections of Amlodipine Besylate (2.8 min.) Amlodipine impurity A (3.7 min.) Atorvastatin impurity A (6.6 min.), Atorvastatin Calcium (7.8 min.), Atorvastatin impurity C (8.7 min.) and Amlodipine impurity B (11.7 min.) respectively under optimized chromatographic conditions.

A. At $100 \%$ conc. Level of all compounds and tablet

B. At DL and QL

Alkaline degradation: Sodium hydroxide $(\mathrm{NaOH})(1 \mathrm{M}, 10 \mathrm{ml})$ was added to $10 \mathrm{ml}$ prepared stock solutions of Amlodipine Besylate, Atorvastatin Calcium and Caduet tablets respectively. These solutions were separately heated at $70^{\circ} \mathrm{C}$ for 2 hours in the dark (to exclude the possible degradative effect of light). The solutions $(2 \mathrm{ml})$ were then transferred to $10 \mathrm{ml}$ volumetric flasks, neutralized by addition of $1 \mathrm{ml}$ of $1 \mathrm{M} \mathrm{HCl}$, and diluted to final volume with diluent $[25,30,31]$.

Oxidation: Hydrogen peroxide $\left(\mathrm{H}_{2} \mathrm{O}_{2} ; 10 \%\right.$, v/v, $\left.10 \mathrm{ml}\right)$ was added to $10 \mathrm{ml}$ prepared stock solutions of Amlodipine Besylate, Atorvastatin Calcium and Caduet tablets respectively. These solutions were separately heated at $70^{\circ} \mathrm{C}$ for 6 hours in the dark. The solutions $(2 \mathrm{ml})$ obtained were then transferred to $25 \mathrm{ml}$ volumetric flasks and diluted to final volume with diluent $[25,30,31]$.

Neutral degradation (Thermal degradation): Prepared stock solutions of Amlodipine Besylate, Atorvastatin Calcium and Caduet tablets respectively were heated at $70^{\circ} \mathrm{C}$ for 6 hours in the dark to study the effect of thermal stress. Also the experiment was performed on solid-state samples which could be stressed under previous condition and then diluted with a known amount of mobile phase. The experiment was performed in the dark to exclude the possible degradative effect of light. The solutions $(1 \mathrm{ml})$ obtained were then transferred to $25 \mathrm{ml}$ volumetric flasks and diluted to finalvolume with diluent $[25,30,31]$.

Photo stability: Prepared stock solutions of Amlodipine Besylate, Atorvastatin Calcium and Caduet tablets respectively $(10 \mathrm{ml})$ were exposed to light providing an overall illumination of not less than 1.2 million lux hours and an integrated near ultraviolet energy of not less than 200 watt hours/square meter. Also the experiment was performed on solid-state samples which could be stressed under previous condition and then diluted with a known amount of mobile phase. The solutions $(1 \mathrm{ml})$ obtained were then transferred to $25 \mathrm{ml}$ volumetric flasks and diluted to final volume with diluent $[25,30,31]$.

\section{Method Validation}

\section{Specificity}

Specificity is the ability to assess unequivocally the analyte in the presence of components which may be expected to be present. Typically these might include impurities, degradants, matrix, etc [32]. A placebo of tablet was prepared by mixing the respective excipients. Solutions were prepared by following the procedure described in the section on sample preparation. The commonly used tablet excipients did not interfere with the method. The diluent chromatogram shows that the tablet diluent has negligible contribution after the void volume at the method detection wavelength of $240 \mathrm{~nm}$. The method were also evaluated by assessing whether impurities like (Amlodipine impurity A, Amlodipine impurity B, Atorvastatin impurity A andAtorvastatin impurity $\mathrm{C}$ ) and degradation products present in the pharmaceutical formulations-obtained from stress studies involving acid, base, peroxide, and heat stored under ICH stability conditions-interfered with the analysis of Amlodipine Besylate and Atorvastatin Calcium (Figure 2A).

Each Caduet film-coated tablet also contains calcium carbonate, croscarmellose sodium, microcrystalline cellulose, pregelatinized starch, polysorbate 80, hydroxypropyl cellulose, purified water, colloidal silicon dioxide (anhydrous), magnesium stearate, Opadry II Blue 85F10919 (polyvinyl alcohol, titanium dioxide, PEG 3000, talc, and FD\&C blue \#2).

\section{Linearity and range}

The linearity of an analytical procedure is its ability (within a given range) to obtain test results which are directly proportional to the concentration (amount) of analyte in the sample. For the establishment of linearity, a minimum of 5 concentrations is recommended [32]. Five Concentrations were chosen in the ranges $(5-15 \mu \mathrm{g} / \mathrm{ml})$ for corresponding levels of $50-150 \% \mathrm{w} / \mathrm{w}$ of the nominal analytical concentration of Amlodipine Besylate and Atorvastatin Calcium. The linearity of peak area responses versus concentrations was demonstrated by linear least square regression analysis. The linear regression equations were $\{\mathrm{Y}=44667 \mathrm{X}-405.02(\mathrm{r}=0.9999)$ and $\mathrm{Y}=41443 \mathrm{X}-2251.4(\mathrm{r}=0.9999)\}$ for Amlodipine Besylate and Atorvastatin Calcium respectively. Where $\mathrm{Y}$ is the peak area of standard solution and $\mathrm{X}$ is the drug concentration.

For impurities of both drugs, weigh $5 \mathrm{mg}$ of Amlodipine impurity A, Amlodipine impurity B, Atorvastatin impurity A and Atorvastatin impurity C $(50 \mathrm{~g} / \mathrm{ml})$ respectively in $100 \mathrm{ml}$ volumetric flask and complete with diluents and sonicate it. Five Concentrations were chosen in the ranges $(1-3 \mu \mathrm{g} / \mathrm{ml})$ for corresponding levels of 50 $150 \% \mathrm{w} / \mathrm{w}$ of the nominal analytical concentration of all impurities respectively. The linear regression equations were $\{\mathrm{Y}=467.93 \mathrm{X}+1187.1$ $(\mathrm{r}=0.9991), \mathrm{Y}=3055.2 \mathrm{X}-3901.2(\mathrm{r}=1.0), \mathrm{Y}=2355.2 \mathrm{X}+1979.7(\mathrm{r}=0.9999)$ and $\mathrm{Y}=2278.7 \mathrm{X}-1943.3 \quad(\mathrm{r}=0.9998)\}$ for Amlodipine impurity $\mathrm{A}$, Amlodipine impurity B, Atorvastatin impurity A and Atorvastatin impurity $\mathrm{C}$ respectively. Where $\mathrm{Y}$ is the peak area of standard solution and $\mathrm{X}$ is the drug concentration.

\section{Precision}

The precision of the assay was investigated by measurement of both repeatability and Intermediate precision. 
Citation: Hafez HM, Elshanawany AA, Abdelaziz LM, Mohram MS (2014) Development of a Stability-Indicating HPLC Method for Simultaneous Determination of Amlodipine Besylate and Atorvastatin Calcium in Bulk and Pharmaceutical Dosage Form. Pharm Anal Acta 5: 316. doi:10.4172/2153-2435.1000316

Repeatability: Repeatability was investigated by injecting a minimum of 9 determinations covering the specified range for the procedure (e.g., 3 concentrations $/ 3$ replicates each) and percentage SD were calculated in Table 1.

Intermediate precision: In the inter-day studies, standard and sample solutions prepared as described above, were analyzed in triplicate on three consecutive days at specified range for the procedure (e.g., 3 concentrations $/ 3$ replicates each) of the test concentration and percentage SD were calculated in Table 1.

\section{Accuracy}

Accuracy was assessed using 9 determinations over 3 concentration levels covering the specified range (80,100 and 120\%). Accuracy was reported in Table 1 as percent recovery by the assay of known added amount of analyte in the sample.

\section{Limits of detection and limits of quantization}

According to the ICH recommendations, determination of limits of detection and quantitation was based on the standard deviation of the $y$-intercepts of regression lines $(n=3)$ and the slope of the calibration plots in Table 2, Figure 2B [32].

\section{System suitability tests}

System suitability tests were used to verify that the resolution and reproducibility were adequate for the performed analysis. The system

\begin{tabular}{|c|c|c|c|c|c|}
\hline \multirow{2}{*}{$\begin{array}{c}\text { Drug } \\
\text { Name }\end{array}$} & \multirow[t]{2}{*}{ Conc. \% } & \multicolumn{2}{|c|}{ Amlodipine Besylate } & \multicolumn{2}{|c|}{ Atorvastatin Calcium } \\
\hline & & $\mathrm{AV} \pm \mathrm{SD} \mathrm{mg} / \mathrm{ml}$ & $\mathrm{AV} \pm \mathrm{SD} \%$ & $\mathrm{AV} \pm \mathrm{SD} \mathrm{mg} / \mathrm{ml}$ & $\mathrm{AV} \pm \mathrm{SD} \%$ \\
\hline \multirow{3}{*}{ 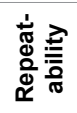 } & $80 \%$ & $8.36 \pm 0.10$ & $100.92 \pm 1.15$ & $8.46 \pm 0.13$ & $100.55 \pm 1.56 \%$ \\
\hline & $100 \%$ & $10.36 \pm 0.03$ & $100.00 \pm 0.26$ & $10.54 \pm 0.07$ & $100.21 \pm 0.68$ \\
\hline & $120 \%$ & $12.40 \pm 0.03$ & $99.77 \pm 0.24$ & $12.58 \pm 0.06$ & $99.63 \pm 0.51$ \\
\hline \multirow{3}{*}{ 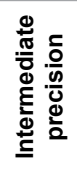 } & $80 \%$ & $8.35 \pm 0.07$ & $100.77 \pm 0.80$ & $8.47 \pm 0.11$ & $100.62 \pm 1.27$ \\
\hline & $100 \%$ & $10.40 \pm 0.06$ & $100.34 \pm 0.61$ & $10.63 \pm 0.18$ & $101.01 \pm 1.72$ \\
\hline & $120 \%$ & $12.40 \pm 0.02$ & $99.73 \pm 0.19$ & $12.59 \pm 0.07$ & $99.75 \pm 0.58$ \\
\hline \multirow{3}{*}{ 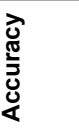 } & $80 \%$ & $8.22 \pm 0.05$ & $99.17 \pm 0.64$ & $8.39 \pm 0.15$ & $99.72 \pm 1.75$ \\
\hline & $100 \%$ & $10.33 \pm 0.05$ & $99.73 \pm 0.46$ & $10.54 \pm 0.11$ & $100.22 \pm 1.04$ \\
\hline & $120 \%$ & $12.32 \pm 0.02$ & $99.1 \pm 0.13$ & $12.54 \pm 0.07$ & $99.37 \pm 0.59$ \\
\hline
\end{tabular}

N.B. $(80 \%, 100 \%$ and $120 \%)$ Concentration of Amlodipine Besylate and Atorvastatin Calcium are $[(8.29,12.43,15.54),(8.42,10.52,12.62)]$ respectively

Table 1: Repeatability, Intermediate precision, Reproducibility and Accuracy of Amlodipine Besylate and Atorvastatin Calcium respectively.

\begin{tabular}{|l|c|c|}
\hline Item & Amlodipine Besylate & Atorvastatin Calcium \\
\hline Linear range $(\mu \mathrm{g} / \mathrm{ml})$ & $5.18-15.54$ & $5.26-15.78$ \\
\hline Detection limit $(\mu \mathrm{g} / \mathrm{ml})$ & 0.16 & 0.17 \\
\hline Quantitation limit $(\mu \mathrm{g} / \mathrm{ml})$ & 0.48 & 0.52 \\
\hline Regression data & - & - \\
\hline No. & 5 & 5 \\
\hline slope $(\mathrm{b})$ & 44667 & 41443 \\
\hline Standard deviation of the slope & 115.01 & 157.99 \\
\hline intercept $(a)$ & -405.02 & -2251.4 \\
\hline Standard deviation of the intercept & 2163.61 & 2152.91 \\
\hline correlation coefficient $®$ & 0.9999 & 0.9999 \\
\hline Standard error of regression & 2407.38 & 1819.8 \\
\hline
\end{tabular}

$(\mathrm{Y}=\mathrm{a}+\mathrm{bC}$, where $\mathrm{C}$ is the concentration of the compound $(\mu \mathrm{g} / \mathrm{ml})$ and $\mathrm{Y}$ is the drug peak area)

Table 2: Calibration data was resulted from method validation of Amlodipine Besylate and Atorvastatin Calcium respectively.

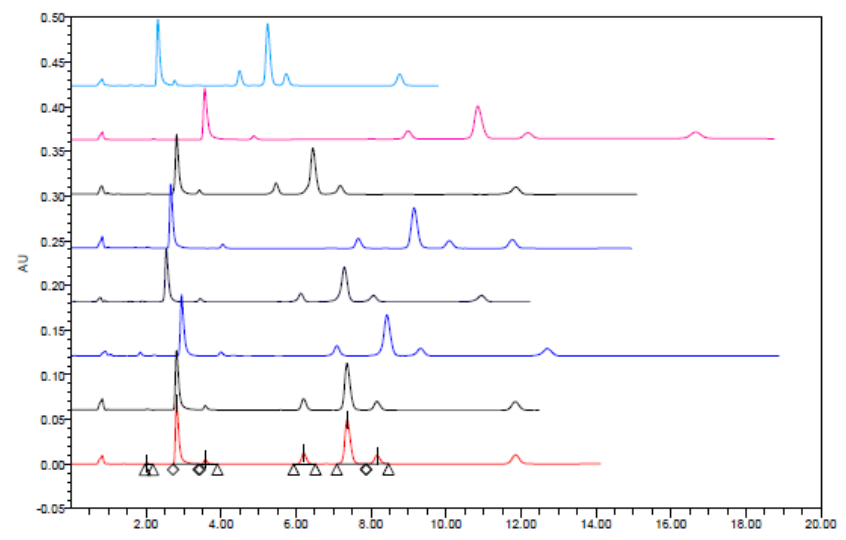

Figure 3: Typical HPLC chromatograms obtained from $20 \mu \mathrm{l}$ injections of Amlodipine Besylate Amlodipine impurity A, Atorvastatin impurity A, Atorvastatin Calcium, Atorvastatin impurity $\mathrm{C}$ and Amlodipine impurity $\mathrm{B}$ respectively under optimized chromatographic conditions. (Ascending order)

1. 2- At 238 and $242 \mathrm{~nm}$

3. 4- at 1.1 and $1.3 \mathrm{ml} / \mathrm{min}$

5. 6-at phosphate buffer $\mathrm{pH}=5.2$ and 5.8

7. 8 -at $33 \%$ and $37 \%$ of acetonitrile

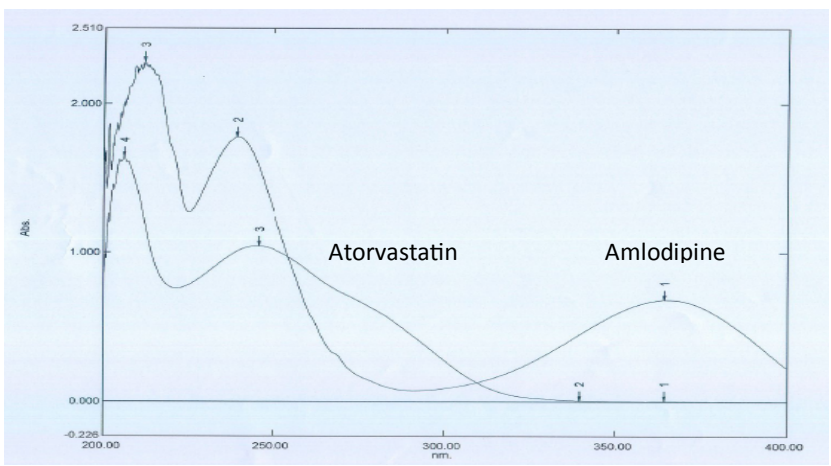

Figure 4: Typical UV spectrum of Amlodipine Besylate and Atorvastatin Calcium respectively.

suitability tests included number of theoretical plates, resolution, peak tailing, capacity factor and selectivity factor. Results are revealed in Table 3 .

\section{Robustness}

Robustness of an analytical procedure is a measure of its capacity to remain unaffected by small variations in method parameters and provides an indication of its reliability during normal usage [32]. Robustness was tested by studying the effect of changing mobile phase $\mathrm{pH}$ by \pm 0.3 , the percentage of organic solvent (Acetontrile) in the mobile phase by $\pm 2 \%$, temperature $\pm 2^{\circ} \mathrm{C}$, wavelengths $\pm 2 \mathrm{~nm}$ and flow rate $\pm 0.1 \mathrm{ml} / \mathrm{min}$ had no significant effect on the chromatographic resolution of the method in Figure 3. Changes in $\mathrm{pH}$ degree and Acetonitrile percent in mobile phase have a greater effect on resolution than other factors(Table 4).

\section{Stability of analytical solution}

Also as part of evaluation of robustness, solution stability was evaluated by monitoring the peak area response. Standard stock 
Citation: Hafez HM, Elshanawany AA, Abdelaziz LM, Mohram MS (2014) Development of a Stability-Indicating HPLC Method for Simultaneous Determination of Amlodipine Besylate and Atorvastatin Calcium in Bulk and Pharmaceutical Dosage Form. Pharm Anal Acta 5: 316. doi:10.4172/2153-2435.1000316

Page 5 of 9

\begin{tabular}{|c|c|c|c|c|c|}
\hline Drugs/Parameters & Theoretical Plates (N) & Resolution (R) & Capacity Factor (K) & Tailing Factor (T) & 1.59 \\
\hline Amlodipine Besylate & 4841.32 & 5.45 & 3.24 & 1.13 \\
\hline Amlodipine impurity A & 8140.99 & 4.96 & 1.38 & 1.36 \\
\hline Atorvastatin impurity A & 10890.33 & 13.56 & 1.09 & 1.18 \\
\hline Atorvastatin Calcium & 11591.13 & 4.61 & 11.27 & 1.05 \\
\hline Atorvastatin impurity C & 12602.44 & 2.87 & 1.21 & 1.07 \\
\hline Amlodipine impurity B & 16468.69 & 11.29 & 1.01 & \\
\hline
\end{tabular}

Table 3: System suitability parameters of all drugs were obtained from Method Validation.

\begin{tabular}{|c|c|c|c|c|c|c|c|c|}
\hline \multirow{2}{*}{$\begin{array}{c}\text { Parameters } \\
\text { Value }\end{array}$} & \multicolumn{2}{|c|}{ Flow Rate } & \multicolumn{2}{|c|}{ PH } & \multicolumn{2}{|c|}{ Acetonitrile \% } & \multicolumn{2}{|c|}{ Wavelength } \\
\hline & 1.1 & 1.3 & 5.2 & 5.8 & 33 & 37 & 238 & 242 \\
\hline Amlodipine Besylate & 4.9 & 4.53 & 4.42 & 5.26 & 8.39 & 3.37 & 5.45 & 5.43 \\
\hline Amlodipine impurity A & 6.29 & 5.86 & 8.87 & 3.94 & 6.93 & 3.34 & 4.96 & 4.92 \\
\hline Atorvastatin impurity $\mathrm{A}$ & 13.99 & 13.35 & 16.7 & 11.07 & 16.12 & 11.03 & 13.56 & 13.51 \\
\hline Atorvastatin Calcium & 4.61 & 4.48 & 5.15 & 4.25 & 5.39 & 3.86 & 4.61 & 4.62 \\
\hline Atorvastatin impurity C & 2.77 & 2.69 & 2.92 & 2.82 & 3.41 & 2.33 & 2.87 & 2.87 \\
\hline Amlodipine impurity B & 8.97 & 8.6 & 14.83 & 14.37 & 9.66 & 12.22 & 11.29 & 11.25 \\
\hline
\end{tabular}

Table 4: Effect of Changes of Some Parameters on Resolution during Method Robustness.
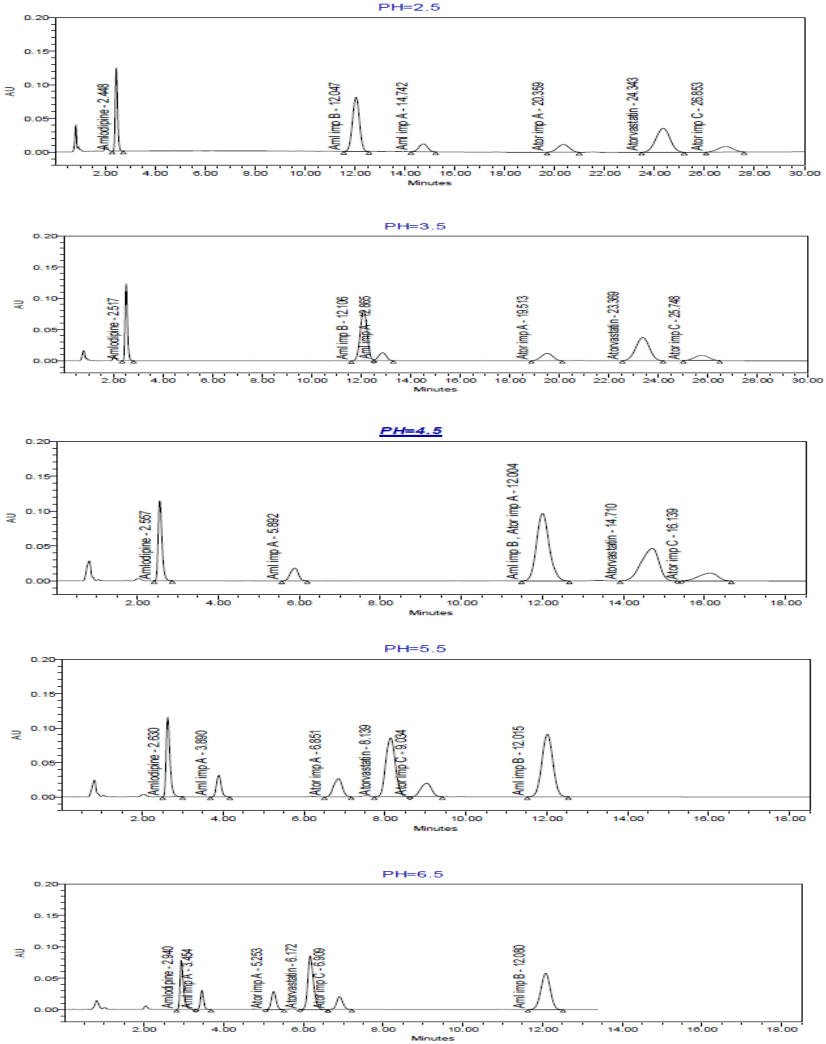

Figure 5: Typical HPLC chromatograms obtained from $20 \mu \mathrm{l}$ injections of Amlodipine Besylate Amlodipine impurity A, B, Atorvastatin Calcium, Atorvastatin impurity $\mathrm{A}$ and $\mathrm{C}$ under chromatographic conditions of mobile phase consisted of acetonitrile 35\%: phosphate buffer $65 \%$ (different $\mathrm{PH}$ ) was pumped on Phenomenex kinetex 2.6 u C18 100A columns at a flow rate 1.2 $\mathrm{ml} / \mathrm{min}$ and detected at $240 \mathrm{~nm}$ at constant temperature $40^{\circ} \mathrm{C}$.

solutions in methanol were analyzed right after its preparation 1,2 and 3 days after at $5^{\circ} \mathrm{C}$. The change in standard solution peak area response over 3 days was ( 0.57 and $0.58 \%$ ) for Amlodipine Besylate, Atorvastatin Calcium respectively. Their solutions were found to be stable for 3 days at $5^{\circ} \mathrm{C}$ at least (Figure 3 ).

\begin{tabular}{|l|c|c|c|c|}
\hline \multirow{2}{*}{ Drug name } & \multicolumn{2}{|c|}{ Recovery \pm SD } & \multirow{2}{*}{ Calculated } & Calculated \\
\cline { 2 - 5 } & $\begin{array}{c}\text { Proposed } \\
\text { methods }\end{array}$ & $\begin{array}{c}\text { Reference } \\
\text { method }\end{array}$ & $\begin{array}{c}\text { f-values } \\
\text { F- values }\end{array}$ \\
\hline Amlodipine Besylate & $100.78 \pm 1.79$ & $100.39 \pm 2.56$ & 0.36 & 0.49 \\
\hline Atorvastatin Calcium & $100.53 \pm 1.23$ & $100.18 \pm 2.02$ & 0.49 & 0.37 \\
\hline
\end{tabular}

(Where the Tabulated t-values and F-ratios at $p=0.05$ are 2.365 and 3.79)

Table 5: Statistical comparison of the proposed and published methods for determination of Amlodipine Besylate and Atorvastatin Calcium respectively in their dosage forms by reported method (T-student test) and (F-test for variance).

\section{Application to Pharmaceutical Preparation}

The proposed methods were successfully used to determine Amlodipine Besylate, Atorvastatin Calcium in Caduet 10/10 mg/tablet. Seven replicate determinations were performed. Satisfactory results were obtained for each compound in good agreement with label claims. The results obtained were compared statistically with those from published method [26] by using Student's t-test and the variance ratio $\mathrm{F}$-test. The results showed that the $\mathrm{t}$ and $\mathrm{F}$ values were smaller than the critical values. So, there were no significant differences between the results obtained from this method and published methods (Table 3).

\section{Results and Discussion}

\section{Optimization of chromatographic condition}

Several trials were carried out to obtain optimized chromatographic condition for simultaneous determination of Amlodipine Besylate and Atorvastatin Calcium in their pharmaceutical preparations.

Firstly, maximum absorption wavelengths $(240 \mathrm{~nm})$ for Amlodipine Besylate and Atorvastatin Calcium were selected by scanning from 350-200 nm under UV (Figure 4).

Potassium Dihydrogen Phosphate buffer has no effect on absorption at wavelengthmore than $200 \mathrm{~nm}$ [33]. Conc. of buffer $(0.03 \mathrm{M})$ is adequate for most reversed phase applications. This concentration is also moderate enough to avoid problems with precipitation when significant amounts of organic modifiers are used in the mobile phase [34].

On the basis of pka of Amlodipine Besylate and Atorvastatin Calcium are 8.6 and 4.5 respectively which means that Amlodipine Besylate has more basic properties than Atorvastatin Calcium due to 
Citation: Hafez HM, Elshanawany AA, Abdelaziz LM, Mohram MS (2014) Development of a Stability-Indicating HPLC Method for Simultaneous Determination of Amlodipine Besylate and Atorvastatin Calcium in Bulk and Pharmaceutical Dosage Form. Pharm Anal Acta 5: 316. doi:10.4172/2153-2435.1000316

Page 6 of 9

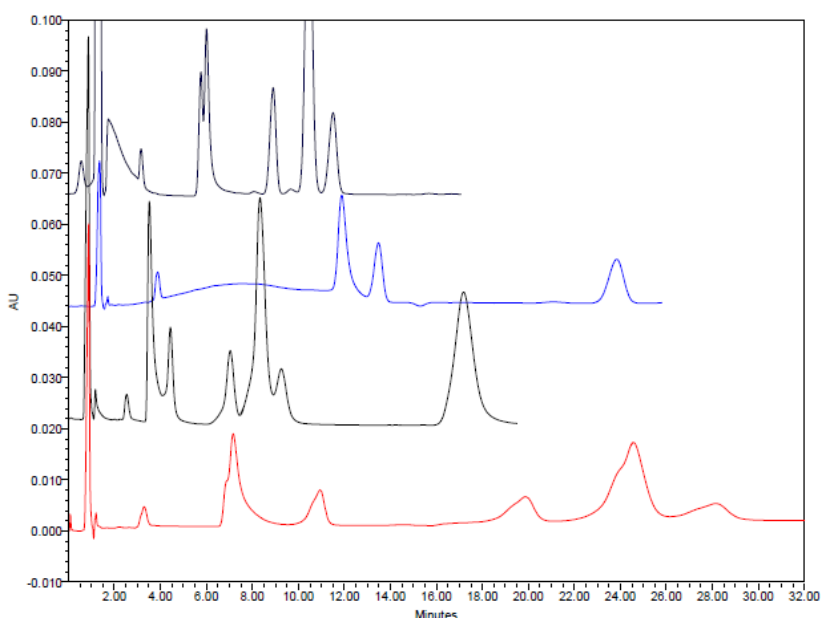

Figure 6: Typical HPLC chromatograms obtained from $20 \mu$ injections of Amlodipine Besylate Amlodipine impurity A, B, Atorvastatin Calcium, Atorvastatin impurity $A$ and $C$ under chromatographic conditions of mobile phase consisted of acetonitrile: phosphate buffer $(\mathrm{PH}=6.5)$ was pumped on columns at a flow rate $1.2 \mathrm{ml} / \mathrm{min}$ and detected at $240 \mathrm{~nm}$ at constant temperature $40^{\circ} \mathrm{C}$. (Ascending order)

1- Agilent eclipse plus C18 (3.5 um, $4.6 \times 100 \mathrm{~mm})$ and acetonitrile $30 \%$

2- Agilent eclipse plus C18 (3.5 um, $4.6 \times 100 \mathrm{~mm})$ and acetonitrile $35 \%$

3- Thermo BDS HYPERSIL C18 (5um, $150 \times 4.6 \mathrm{~mm}$ ) and acetonitrile $30 \%$

4- Thermo BDS HYPERSIL C18 (5um, $150 \times 4.6 \mathrm{~mm}$ ) and acetonitrile $35 \%$

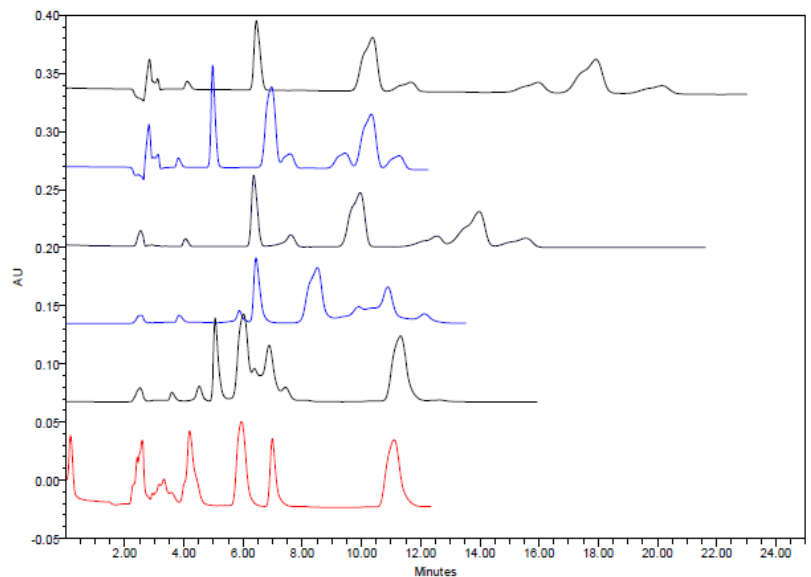

Figure 7: Typical HPLC chromatograms obtained from $20 \mu \mathrm{l}$ injections of Amlodipine Besylate Amlodipine impurity A, B, Atorvastatin Calcium, Atorvastatin impurity $\mathrm{A}$ and $\mathrm{C}$ under chromatographic conditions of a mobile phase consisted of acetonitrile: phosphate buffer was pumped on Thermo BDS HYPERSIL Cyano (5um, $250 \times 4.6 \mathrm{~mm}$ ) column at a flow rate $1.2 \mathrm{ml} /$ min and detected at $240 \mathrm{~nm}$ at constant temperature $40^{\circ} \mathrm{C}$. (Ascending order)

1-acetonitrile $35 \%$ : phosphate buffer $65 \% \quad \mathrm{PH}=6.5$

2-acetonitrile $35 \%$ : phosphate buffer $65 \% \quad \mathrm{PH}=4.5$

3-acetonitrile $30 \%$ : phosphate buffer $70 \% \quad \mathrm{PH}=4.5$

4-acetonitrile $25 \%$ : phosphate buffer $75 \% \quad \mathrm{PH}=4.5$

5-acetonitrile $35 \%$ : phosphate buffer $65 \% \quad \mathrm{PH}=2.5$

6-acetonitrile $30 \%$ : phosphate buffer $65 \% \quad \mathrm{PH}=2.5$ free and cyclic amino group and vice versa Atorvastatin Calcium has free carboxylic group. Several degrees of $\mathrm{pH}$ of phosphate buffer (2.56.5) were examined (Figure 5). At lower (2.5-3.5), it shows a fast eluting of amlodipine (it becomes difficult to separate it from its predictable degradation products, lately one for atorvastatin (long time about 25 min) and co-elution between Amlodipine imp A and Amlodipine imp B. At 4.5, there is interference between Amlodipine imp B and atorvastatin imp A.

A good separation had obtained at higher (5.5-6.5), 5.5 is more suitable than 6.5 because resolution between Amlodipine and its impurity $\mathrm{A}$ are greater than resolution between atorvastatin and its impurity $\mathrm{C}$ at 5.5 and the former is more critical than the latter one as it is more affected by increasing in organic solvent percentage.

Several types of columns were tried like Agilent eclipse plus C18 $(3.5 \mu \mathrm{m}, 4.6 \times 100 \mathrm{~mm})$, Thermo BDS HYPERSIL C18 $(5 \mu \mathrm{m}, 150 \times 4.6$ $\mathrm{mm})$ and Thermo BDS HYPERSIL Cyano $(5 \mu \mathrm{m}, 250 \times 4.6 \mathrm{~mm})$ in addition to enomenexkinetex $2.6 \mu \mathrm{m} \mathrm{C18} \mathrm{100A}(100 \times 4.6 \mathrm{~mm})$. The first and second columns have bad peak shape and resolution (Figure 6). On cyano column, order of peaks was changed atorvastatin early eluted than amlodipine which resulted in further examination at differentand organic solvent percentages but finally we did not have good peak shape or resolution (Figure 7).

Ammonium acetate and sodium dihydrogenosate were also tried, no significant difference between sodium dihydrogenosate and potassium dihydrogenosate but Ammonium acetate give less resolution power (Figure 8)

Methanol exhibits poor separation and peak shape as an organic solvent (Figure 9).

After all of previous had been carried out, our previous mentioned optimized chromatograic conditions were selected.

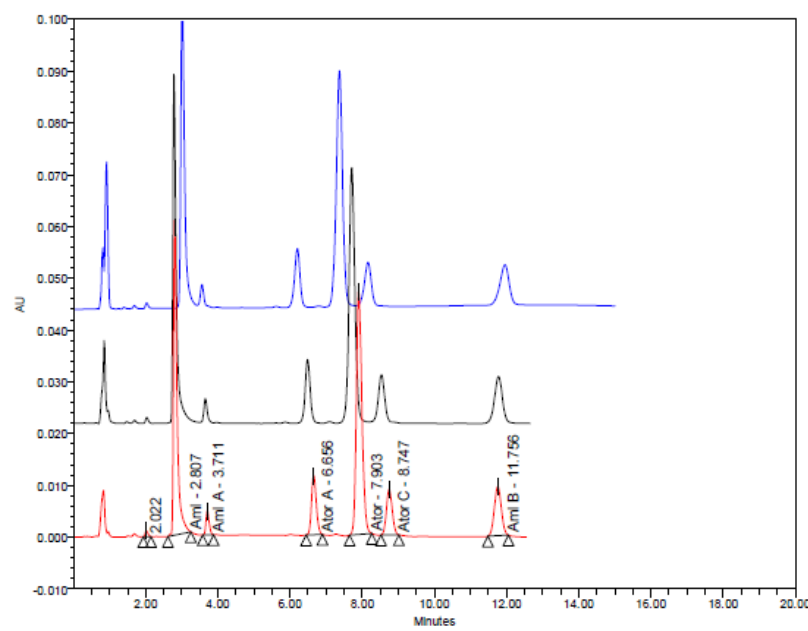

Figure 8: Typical HPLC chromatograms obtained from $20 \mu \mathrm{l}$ injections of Amlodipine Besylate Amlodipine impurity A, B, Atorvastatin Calcium, Atorvastatin impurity $\mathrm{A}$ and $\mathrm{C}$ under chromatographic conditions of mobile phase consisted of acetonitrile 35\%: aqueous buffer $65 \%(\mathrm{PH}=5.5)$ was pumped on Phenomenex kinetex 2.6 u C18 100A columns at a flow rate 1.2 $\mathrm{ml} / \mathrm{min}$ and detected at $240 \mathrm{~nm}$ at constant temperature $40^{\circ} \mathrm{C}$. (Ascending order)

1-potassium dihydrogen phosphate

2-sodium dihydrogen phosphate

3-Ammonium acetate 
Citation: Hafez HM, Elshanawany AA, Abdelaziz LM, Mohram MS (2014) Development of a Stability-Indicating HPLC Method for Simultaneous Determination of Amlodipine Besylate and Atorvastatin Calcium in Bulk and Pharmaceutical Dosage Form. Pharm Anal Acta 5: 316. doi:10.4172/2153-2435.1000316

Page 7 of 9

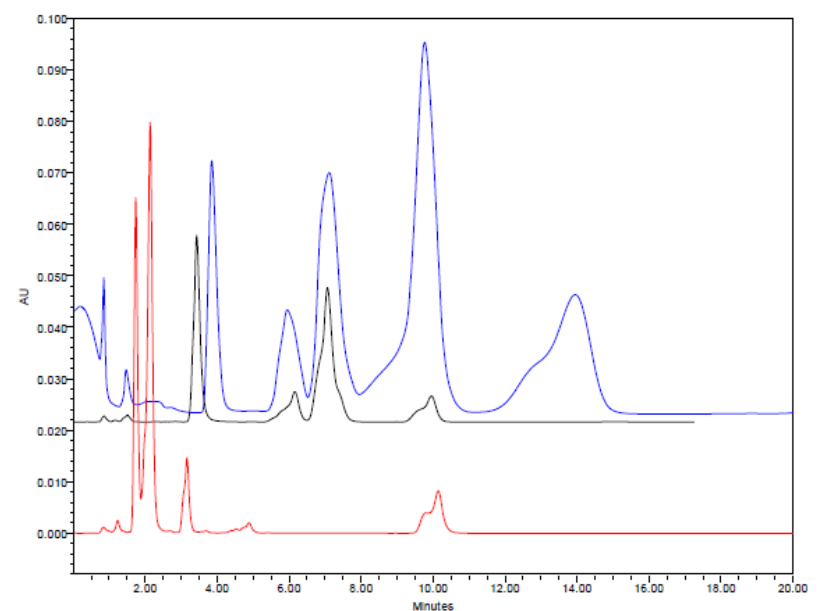

Figure 9: Typical HPLC chromatograms obtained from $20 \mu$ injections of Amlodipine Besylate Amlodipine impurity A, B, Atorvastatin Calcium, Atorvastatin impurity $A$ and $C$ under chromatographic conditions of mobile phase consisted of methanol: phosphate buffer $(\mathrm{PH}=5.5)$ was pumped on Phenomenex kinetex $2.6 \mathrm{u} \mathrm{C18} 100 \mathrm{~A}$ columns at a flow rate $1.2 \mathrm{ml} / \mathrm{min}$ and detected at $240 \mathrm{~nm}$ at constant temperature $40^{\circ} \mathrm{C}$. (Ascending order)

1-Methanol $65 \%$

2-Methanol $55 \%$

3-Methanol 45\%

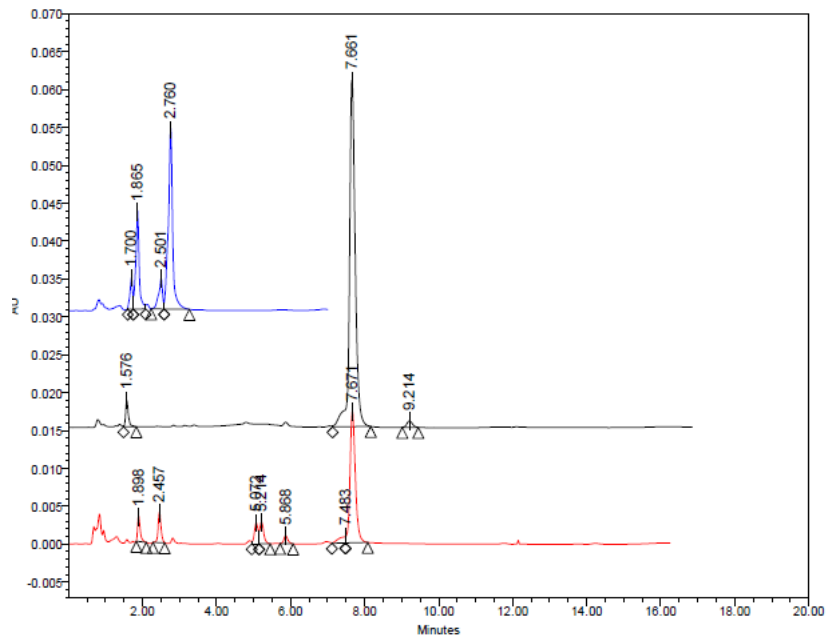

Figure 10: Typical HPLC chromatograms obtained from $20 \mu$ injections of solutions of Amlodipine Besylate, Atorvastatin Calcium and Caduet tablet which were subjected to acidic condition under optimized chromatographic conditions. (Descending order).

\section{Forced degradation studies}

If the compound is poorly water-soluble, organic co-solvents may be used in combination with acid or base. Organic solvents that have been commonly used for stress-testing studies are DMSO, acetic acid acetonitrile and methanol. As usual, when conducting stress testing, the analyst should be wary of possible side reactions that may affect the drug, for example, methanol should be avoided for compounds containing $-\mathrm{CO} 2 \mathrm{H},-\mathrm{CO} 2 \mathrm{R}$, amide groups. Acetonitrile is the cosolvent of choice for otochemical reaction [30]. Amlodipine Besylate, Atorvastatin calcium authentic standards and Caduet tablets were subjected to various stress condition. In acidic conditions, both

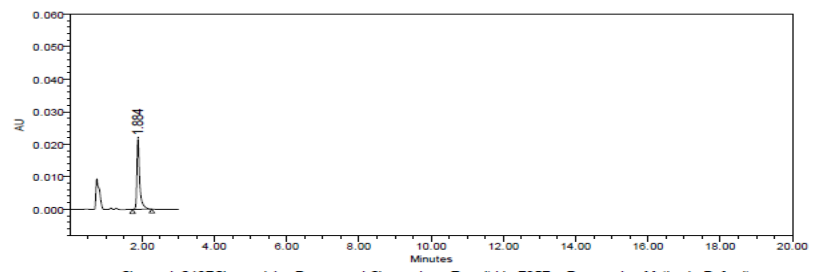

Figure 11a: Typical HPLC chromatograms obtained from $20 \mu \mathrm{l}$ injections of solutions of Amlodipine Besylate impurity D (pyridine analogue) under optimized chromatographic conditions.<smiles>CCOC1OC(=O)C2=C(COCCN)NC(C)=C(C(=O)OC)[C@H]2c2ccccc21</smiles>

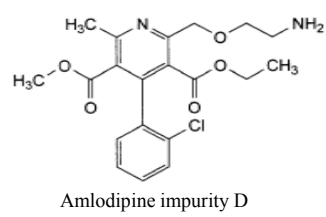

Figure 11b: Degradation pathway of amlodipine by acid, peroxide or light.

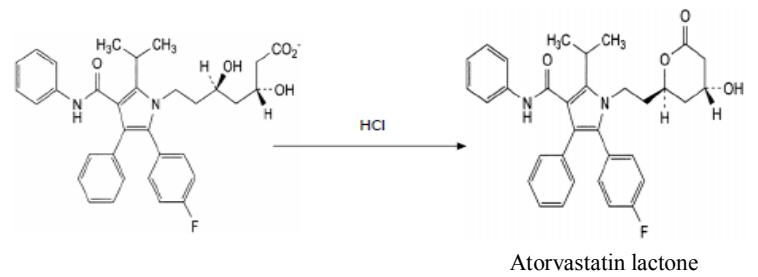

Figure 11C: Degradation pathway of Atorvastatin by acid.

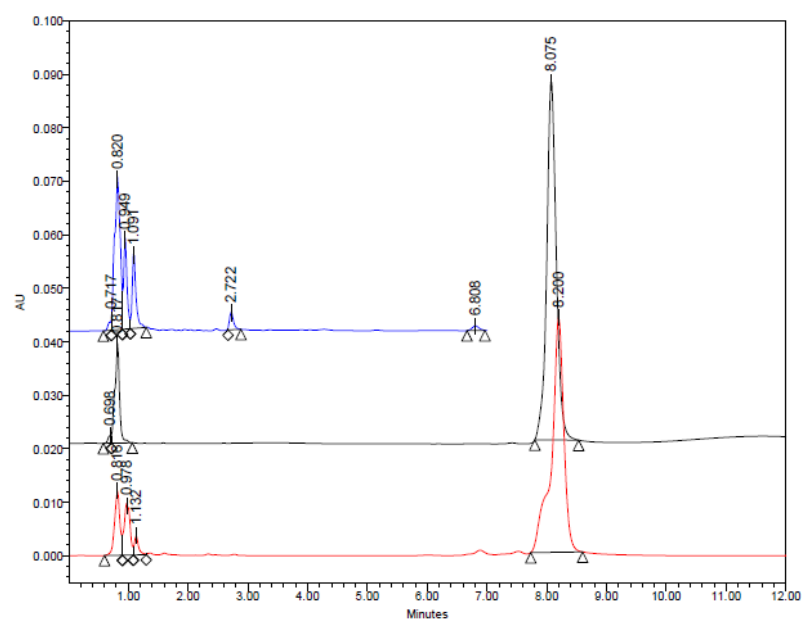

Figure 12: Typical HPLC chromatograms obtained from $20 \mu$ injections of solutions of Amlodipine Besylate, Atorvastatin Calcium and caduet tablet which were subjected to alkaline condition under optimized chromatographic conditions. (Descending order)

drugs exhibited high percentage of degradation about $79 \%$ and $62 \%$ for Amlodipine Besylate and Atorvastatin calcium respectively (Figure 10). The pyridine analogue of Amlodipine (impurity D) and Atorvastatin lactone (impurity $\mathrm{G}$ ) were the main degradation products of Amlodipine Besylate and Atorvastatin calcium respectively (Figure 
Citation: Hafez HM, Elshanawany AA, Abdelaziz LM, Mohram MS (2014) Development of a Stability-Indicating HPLC Method for Simultaneous Determination of Amlodipine Besylate and Atorvastatin Calcium in Bulk and Pharmaceutical Dosage Form. Pharm Anal Acta 5: 316. doi:10.4172/2153-2435.1000316

Page 8 of 9

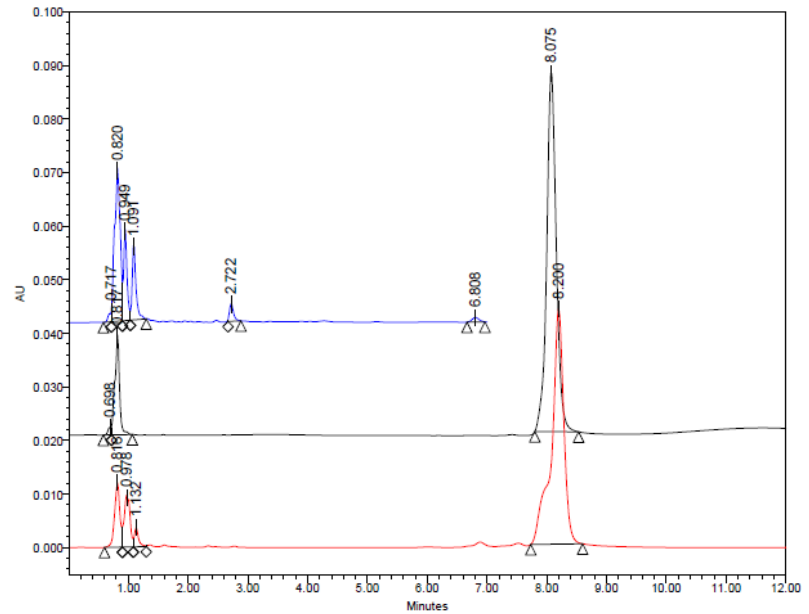

Figure 13: Typical HPLC chromatograms obtained from $20 \mu$ injections of solutions of Amlodipine Besylate, Atorvastatin Calcium and caduet tablet which were subjected to thermal condition under optimized chromatographic conditions. (Descending order)

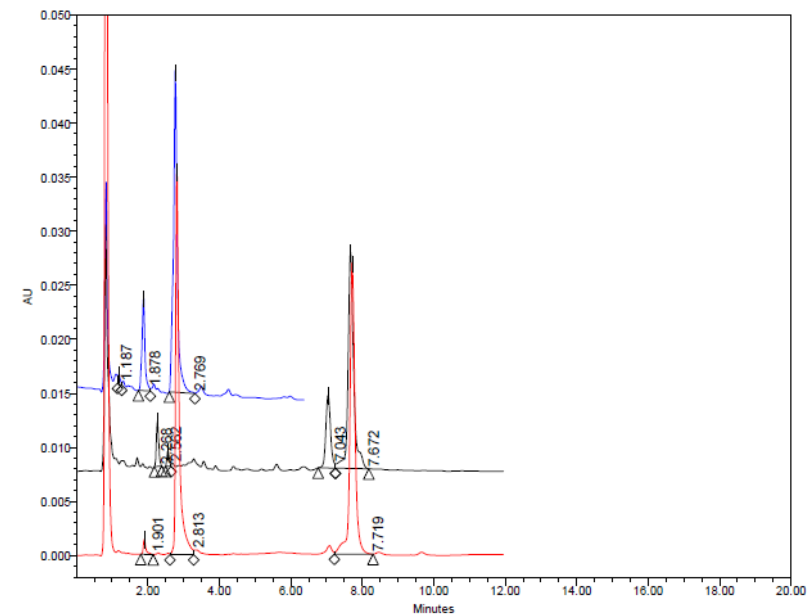

Figure 14: Typical HPLC chromatograms obtained from $20 \mu$ injections of solutions of Amlodipine Besylate, Atorvastatin Calcium and caduet tablet which were subjected to oxidative condition under optimized chromatographic conditions. (Descending order)

11a-11c). In alkaline conditions, both drugs degraded about $95 \%$ and $14 \%$ for Amlodipine Besylate and Atorvastatin calcium respectively. The major degradation products of Amlodipine Besylate eluted early at 0.9 and 1.09 minute (Figure 12). Amlodipine Besylate and Atorvastatin calcium are more stable under neutral degradation (Thermal degradation); only about $13 \%$ degradation of two drugs was observed (Figure 13). In oxidative conditions, both drugs were found to be highly labile to oxidative hydrolysis in $10 \% \mathrm{H}_{2} \mathrm{O}_{2}$ at $70 \%$ after 6 hours. Approximately 80\%, 75\% degradation was observed for Amlodipine Besylate and Atorvastatin calcium respectively due to its nitrogenous content. The major degradation product of Amlodipine Besylate was its pyridine analogue (Figure 14). Both drugs were affected significantly by otolyticdegradation (Figure 15).

\section{Discussion}

New developed method has several merits than other published

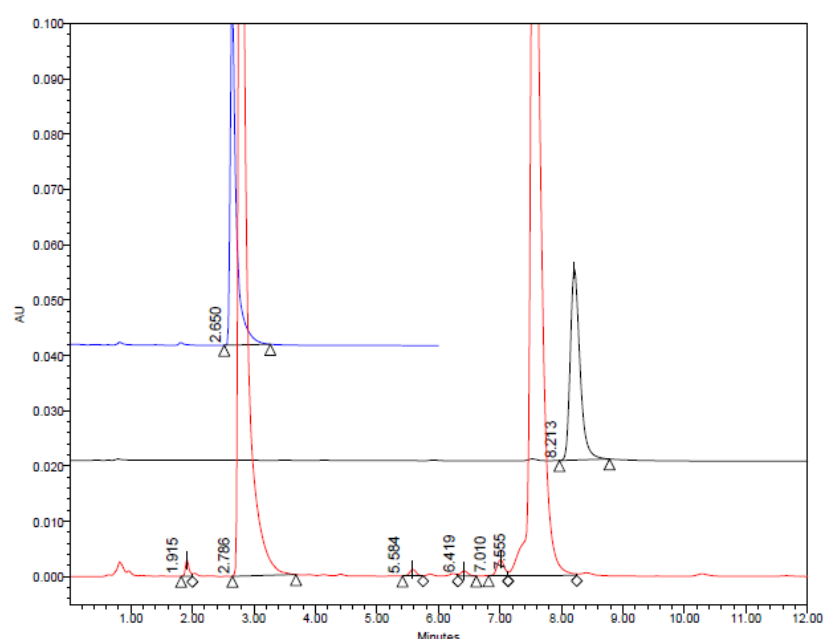

Figure 15: Typical HPLC chromatograms obtained from $20 \mu$ injections of solutions of Amlodipine Besylate, Atorvastatin Calcium and caduet tablet which were subjected to photolytic degradation under optimized chromatographic conditions. (Descending order)

methods in literature, it didn't use ion pair buffer in mobile ase like RJ Eranki et al. [28] which shorten column life time and require long time for system stabilization and column washing. Run time is shorter and sensitivity is more than Turabi et al. [29]. Specificity was proven clearly after impurities of both drugs had been separated in addition to degradation products which were identified and its pathways were mentioned, in contrary to BG Chaudhari et al. [27]. Mohammadi et al. [26] didn't mention how to optimize and develop his method and little information about system suitability test.

\section{Conclusion}

A simple, accurate, precise, robust and reliable LC method has been established as stability indicating method for Amlodipine Besylate and Atorvastatin Calcium respectively in bulk and in their pharmaceutical dosage form.

\section{References}

1. Bashir S, Sherwanil K, Shabbir I, Batool A (2011) Efficacy of Fix Dose Combination (Atorvastatin And Amlodipine) In Treatment of Uncontrolled Hypertension and Dyslipidemia, J Ayub Med Coll Abbottabad 23: 97-100.

2. Ogbru O (2014) Caduet (amlodipine besylate, atorvastatin calcium) drug.

3. Alnajjar AO (2012) Simultaneous Determination of Amlodipine and Atorvastatin in Tablet Formulations and Plasma using Capillary Electrophoresis, LCGC Europe 25: 3.

4. Health wise Knowledgebase (2014) US Pharmacopoeia, Rockville.

5. (2013) British Pharmacopoeia (6 $6^{\text {th }}$ edition) London.

6. Çelebier M, Kaynak MS, Altınöz S, Sahin S (2010) HPLC method development for the simultaneous analysis of amlodipine and valsartan in combined dosage forms and in vitro dissolution studies, Brazilian J Pharm Sci 46: 761-768.

7. Hotha KK, Yarramu NR, Kandibedala T, Dasari VB, Vobalaboina V (2012) Simultaneous Determination of Atorvastatin and Glimepiride by LC-MS/MS in Human Plasma and Its Application to a Pharmacokinetic Study, American J Anal Chem 3: 559-569.

8. Muthu AK, Gupta TR, Sharma S, Smith AA, Manavalan R, et al. (2008) Simultaneous Estimation of Amlodipine and Atorvastatin in Tablets Using Orthogonal Function Ratio Spectrometry, Int J Chem Sci 6: 2233-2241.

9. Amir HM, Konoz E, Ghiyasvand M (2011) Simultaneous Determination of Atorvastatin Calcium and Amlodipine Besylate by Spectrophotometry and 
Citation: Hafez HM, Elshanawany AA, Abdelaziz LM, Mohram MS (2014) Development of a Stability-Indicating HPLC Method for Simultaneous Determination of Amlodipine Besylate and Atorvastatin Calcium in Bulk and Pharmaceutical Dosage Form. Pharm Anal Acta 5: 316. doi:10.4172/2153-2435.1000316

Multivariate Calibration Methods in Pharmaceutical Formulations, E-J Chem 8: $1670-1679$.

10. Ramesh D, Ramakrishna S (2010) New Spectrophotometric Methods for Simultaneous Determination of Amlodipine Besylate and Atorvastatin Calcium in Tablet Dosage Forms, Int J Pharm Pharm Sci 2: 4.

11. Sohrabi MR, Abdolmaleki P, Dehroudi M (2013) Simultaneous quantitative determination of Amlodipine and Atorvastatin in tablets using artificial neural networks, Mathematical and Computer Modelling 58: 1588-1594.

12. Patel VB, Sahu R, Patel BM (2011) Simultaneous determination of Amlodipine besylate and Atorvastatin calcium in Pharmaceutical tablet formulation by High Performance Thin Layer Chromatographic method, Int J Chem Tech Res 3: 695-698.

13. Moussa BA, El-Zaher AA, Mahrouse MA, Ahmed MS (2013) Simultaneous Determination of Amlodipine Besylate and Atorvastatin Calcium in Binary Mixture by Spectrofluorimetry and HPLC Coupled with Fluorescence Detection, Anal Chem Insights 8: 107-115.

14. Abdallaha OM, Badawey AM (2011) Derivative-Ratio Spectrophotometric Chemometric and HPLC Validated methods for Simultaneous Determination of Amlodipine and Atorvastatin in Combined Dosage Form, Int J Ind Chem 2 78-85.

15. Silvia I, Klara K, Lucia MD (2013) Simultaneous Determination of Atorvastatin and Amlodipine in Industrial Tablets by Apparent Content Curve and HPLC Methods, Acta Medica Marisiensis 59: 44-48

16. Reddy TN, Banda SD, Srinivas GD (2013) Design and Development of Fas Dissolving Tablet of Amlodipine Besylate and Atorvastatin Calcium, Int J Pharm Sci Rev Res 23: 290-294.

17. Shah DA, Bhatt KK, Mehta RS, Baldania SL, Gandhi TR (2008) Stability indicating RP-HPLC estimation of atorvastatin calcium and amlodipine besylate in pharmaceutical formulations, Indian J Pharm Sci 70: 754-760.

18. Yacoub M, Abu awwad A, Alawi M, Arafat T (2013) Simultaneous determination of amlodipine and atorvastatin with its metabolites; ortho and parahydroxy atorvastatin; in human plasma by LC-MS/MS, J Chromatogr B :917-918.

19. Yu Q, Yi Hu Z, Yuan Zhu, Hui Zhu J, Li Wan L, et al. (2011) HPLC-MS-MS for the Simultaneous Determination of Atorvastatin and Amlodipine in Plasma of Hypertensive Patients, Chromatographia 73: 257-262.

20. Zhou Y, Li J, He X, Jia M, Liu M, et al. (2013) Development and validation of a liquid chromatography-tandem mass spectrometry method for simultaneous determination of amlodipine, atorvastatin and its metabolites ortho-hydroxy atorvastatin and para-hydroxyatorvastatin in human plasma and its application in a bioequivalence study, J Pharm Biomed Anal 83: 101-107.
21. Mallikarjuna S, Ramalingam P, Sriram P, Garima J, Srinivas SK (2013) Development and Validation of Stability-Indicating RP-UPLC Method for Simultaneous Estimation of Amlodipine Besylate and Atorvastatin Calcium in Pharmaceutical Dosage Forms, J Chromatogr Separat Techniq 4: 187-192.

22. Waghmare AN, Muddukrishna BS, Vasantharaju SG (2014) Analytical Method Development and Validation of Simultaneous Estimation of Amlodipine and Atorvastatin by RP-UPLC, Mintage J Pharm Med Sci 3: 22-25.

23. Pathak A, Rajput SJ (2009) Development of a Stability-Indicating HPLC Method for Simultaneous Determination of Olanzapine and Fluoxetine in Combined Dosage Forms, J Chromatogr Sci 47: 605-611.

24. International Conference on Harmonization (2003) Stability testing of new drug substances and products, IFPMA, Geneva, Switzerland.

25. International Conference on Harmonization (1996) Stability testing: Photostability testing of new drug substances and products. International Conference on Harmonization, IFPMA, Geneva, Switzerland.

26. Mohammadi A, Rezanour N, Ansari Dogaheh M, Ghorbani Bidkorbeh F, Hashem M, et al. (2007) A stability-indicating high performance liquid chromatographic (HPLC) assay for the simultaneous determination of atorvastatin and amlodipine in commercial tablets, J Chromatogr B Analyt Technol Biomed Life Sci 846: 215-221.

27. Chaudhari BG, Patel NM, Shah PB (2007) Stability Indicating RP-HPLC Method for Simultaneous Determination of Atorvastatin and Amlodipine from Their Combination Drug Products, Chem Pharm Bull 55: 241-246.

28. Eranki RJ, Inti G, Jayaraman V, Vidiyala SR, Ramulu JS (2013) New Stability Indicating Method for Quantification of Impurities in Amlodipine and Atorvastatin calcium Tablets by Validated HPLC, Int J Pharm Res Scholars 2: 458-471.

29. Turabi ZM, Khatatbeh OA (2013) Stability Indicating RP-HPLC Method Development and Validation for the Simultaneous Determination of Atorvastatin and Amlodipine in Pharmaceutical Dosage Forms, J Pharma Research 2: 8-13.

30. Huynh-Ba K (2009) Handbook of Stability Testing in Pharmaceutical Development ( $1^{\text {st }}$ edition) Springer Science and Business Media, LLC New York, USA.

31. Baertschi SW (2005) Pharmaceutical Stress Testing, Predicting Drug Degradation (1st edn) Taylor and Francis Group, New York.

32. ICH Harmonized Tripartite Guideline, Validation of Analytical Procedures: Text and Methodology.

33. Sethi PD (2001) High Performance liquid Chromatography quantitative analysis of pharmaceutical formulations.

34. Preparing Buffered Mobile Phases for Reversed Phase HPLC. 